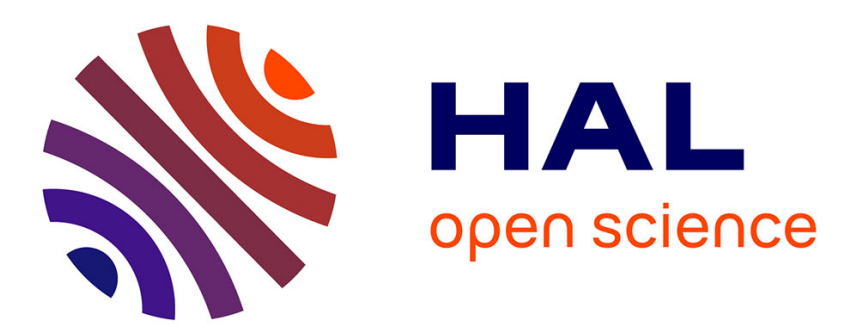

\title{
Indeterminacy with constant money growth rules and income-based liquidity constraints
}

\author{
Stefano Bosi, Frederic Dufourt
}

\section{To cite this version:}

Stefano Bosi, Frederic Dufourt. Indeterminacy with constant money growth rules and income-based liquidity constraints. Research in Economics, 2008, 62 (2), pp.57-63. 10.1016/j.rie.2008.04.002 . hal00796231

\section{HAL Id: hal-00796231 \\ https://hal.science/hal-00796231}

Submitted on 2 Mar 2013

HAL is a multi-disciplinary open access archive for the deposit and dissemination of scientific research documents, whether they are published or not. The documents may come from teaching and research institutions in France or abroad, or from public or private research centers.
L'archive ouverte pluridisciplinaire HAL, est destinée au dépôt et à la diffusion de documents scientifiques de niveau recherche, publiés ou non, émanant des établissements d'enseignement et de recherche français ou étrangers, des laboratoires publics ou privés. 


\title{
Indeterminacy with Constant Money Growth Rules and Income-Based Liquidity Constraints
}

\author{
Stefano Bosi* \\ EPEE, University of Evry \\ Frédéric Dufourt ${ }^{\dagger}$ \\ BETA-Theme, University Louis Pasteur
}

December 20, 2006

\begin{abstract}
We study the implications of constant money growth rules on the stability properties of the equilibrium, in economies where agents are subject to a partial cash-in-advance constraint applying simultaneously to consumption and investment purchases. By reference to similar models in which the liquidity constraint applies only to consumption, we show that the inclusion of investment has dramatic, but contrasting, effects on the range of values giving rise to indeterminacy. First, it increases strongly a lower bound on the share of purchases requiring cash, below which the steady state is always indeterminate. Second, it creates a higher bound on this share, above which the steady-state is always determinate. In this context, the steady state value of the velocity of money becomes a crucial parameter for gauging whether constant money growth rules may be stabilizing or destabilizing for the economy.

Keywords: Cash-in-advance, indeterminacy, business cycles.

JEL Classification: D90, E32, E41.
\end{abstract}

\footnotetext{
${ }^{*}$ Corresponding author. EPEE, Department of Economics, University of Evry, 4, bd F. Mitterrand, 91025 Evry cedex, France. Tel: 00331694770 52. Fax: 0033169477050. E-mail: stefano.bosi@univ-evry.fr.

${ }^{\dagger}$ BETA, University Louis Pasteur - Strasbourg I, 61 Avenue de la Forêt Noire, F67085 Strasbourg Cedex, France. Tel: 00333902421 05. Fax: 00333902420 71. E-mail: dufourt@cournot.u-strasbg.fr.
} 


\section{Introduction}

Money non-neutrality is a feature of a world characterized by a degree of market imperfection. When a monetary policy affects the real sphere, it is not unworthy to address the issue of whether and how economic dynamics could be perturbed by this policy rule. In the last three decades a growing literature has focused on the risk of economic fluctuations associated to the implementation of a wrong rule. Rules based on a quantity or a price control such as, respectively, a constant money growth rule or an interest rate pegging, have been observed through the prism of stability. More recently, more sophisticated policies such as the Taylor's rules have been criticized as potential sources of economic instability. ${ }^{1}$

Before choosing a policy rule according to any welfare-maximizing criterion, we need to know as a matter of priority whether the rule introduces multiple equilibria and expectations-driven fluctuations. The answer to this question of course will depend on the kind of market imperfections that is taken into account.

On the one hand, the simplest way to justify the money demand is to assume a credit market imperfection through a cash-in-advance constraint. ${ }^{2}$ On the other hand, the simplest form of money supply is a constant (possibly zero) monetary growth. Both sides give rise to the simplest form of monetary equilibrium.

The goal of the paper is to shed a light on the stability properties of such an equilibrium: we will provide clear-cut conditions on the structural parameters in order to point out the fundamentals layout that make a constant money growth a dangerous source of fluctuations.

One may wonder that such a so simple setting has been definitely characterized by scholars during the last decade.

In particular, two influential papers have focused on the stabilizing role of a money growth targeting rule with differing recommendations. However a puzzling question remains unanswered in the literature. On the one side Cooley and Hansen (1989) have shown that, when the cash-in-advance constrains the consumption purchases, there is room for expectations-driven fluctuations; on the other side Abel (1985) proved that, when the CIA concerns in addition the investment expenditure, the equilibrium multiplicity is ruled out.

Our paper is an attempt to criticize the robustness of Abel's conclusion. In order to reconcile the Cooley and Hansen view with the Abel's one, we draw on a recent contribution by Bosi and Magris (2003).

These authors study the consequences of a partial cash-in-advance on consumption expenditures in the spirit of Grandmont and Younès (1972). ${ }^{3}$ Inde-

\footnotetext{
${ }^{1}$ See, among the others, Benhabib et alii (2001) for a global bifurcation analysis.

2 The approaches CIA (cash-in-advance; Clower, 1967) and MIUF (money-in-the-utilityfunction; Sidrauski, 1967) stress the transaction motive for money holding. The latter is more general than the former (Feenstra, 1986).

${ }^{3}$ A close reference is Lucas and Stokey (1987), that is, an economy with a cash and a credit good. Woodford (1994) demonstrated the possibility of endogenous fluctuations with constant
} 
terminacy is shown to prevail for any value of the intertemporal elasticity of substitution, provided that the share of consumption purchases requiring cash in advance is below a certain threshold. When the share is above that threshold, indeterminacy arises only when the relative risk aversion of households is high enough (greater than 2, for example, in the standard Cooley and Hansen (1989) model with full liquidity constraint on consumption). However, as these values typically fall within the (admittedly imprecise) range of empirically plausible estimates for that parameter, these findings tend to suggest that constant money growth rules may be ineffective in ruling out indeterminacy and sunspot-driven fluctuations when financial imperfections such as liquidity constraints are at stake in the economy.

The conclusion is criticized by Carlstrom and Fuerst (2003). In line with Feenstra (1986), they build a dynamic model where a CIA constraint on consumption expenditures is viewed as a case of perfect complementarity between real balances and consumption in the utility function. In their paper money demand depends not only on consumption, but also on the nominal interest rate, a desirable feature from an empirical perspective. They show that indeterminacy quickly disappears as soon as the interest-elasticity of money demand increases. As their economy is locally determinate for realistic estimates of this elasticity, Carlstrom and Fuerst conclude that money growth targeting rules are likely to stabilize the economy.

Our paper does not aim to solve the issue of the sensitivity of indeterminacy results in CIA economies when allowing for a non-zero interest rate elasticity of money demand. But it recognizes that the functional equivalence which is central to the results in Carlstrom and Fuerst (2003) is restrictive to the case in which the cash-in-advance constraint applies only to consumption purchases. From an empirical purpose, assuming that liquidity constraints concern only consumption purchases may be seen as implausible as assuming a zero interestelasticity of money demand. But as soon as liquid assets are also needed to finance a share of investment streams (as the business cycle literature on investment strongly emphasizes), Feenstra's functional equivalence and results derived in a MIUF context no longer apply to economies in which agents are submitted to liquidity constraints.

But, what does it happen if the assumption of partial cash-in-advance is extended to the investment? If we suppose that an exogenous share $q \in(0,1]$ of consumption and investment expenditures needs cash, equilibrium determinacy is no longer ensured.

More precisely, we find two critical values of the share, say $q_{1}$ and $q_{2}$, such that if $q$ is below $q_{1}$ we are in a world $\grave{a} l a$ Bosi and Magris (2003) (indeterminacy for whatever degree of intertemporal substitutability); if $q$ lies between $q_{1}$ and $q_{2}$, we are in an economy à la Cooley and Hansen (1989) (indeterminacy for low degree of intertemporal sustitutability, that is strong income effects or large risk aversion); if, eventually $q$ is beyond $q_{2}$ (possibly close to one) the world behaves

money growth rules in a world à la Lucas and Stokey. Indeterminacy issues in more general MIUF models have been addressed by Matsuyama (1990). 
à $l a$ Abel and the equilibrium turns out to be unique whatever the magnitude of the income effects (or the degree of risk aversion).

So, Abel can be viewed as a particular case. However, our paper addresses also a question of empirical plausibility and whishes to investigate the robustness of the indeterminacy findings. We study whether the inclusion of investment in the liquidity constraint strongly modifies the range of parameters values giving rise to indeterminacy, by comparison to the reference economy studied in Bosi and Magris (2003) in which this constraint applies only to consumption. As seen above, our results show that it does, but in a way which is contrasted for the indeterminacy region: the inclusion of investment strongly increases a lower bound on the share of good purchases requiring cash below which the steady state is always indeterminate, but it creates a higher bound on this share above which the steady-state is always determinate. The stabilizing or destabilizing effects of constant money growth rule on the economy therefore depend crucially on the strength of the liquidity constraints - a parameter which, in the model, can also be interpreted as the (inverse of) the steady-state velocity of money. Empirical estimates for that parameter suggest that the economy have been in the determinacy zone during the recent decades, but that the observed upward trend of velocity in the US economy may quickly lead to a reversal of this conclusion.

The remainder of the paper is organized as follows. Section 2 sets up the model economy, derives the intertemporal equilibrium and characterizes the (unique) steady-state. Section 3 provides the stability analysis, and discusses the conditions for local indeterminacy. Section 4 concludes.

\section{The model}

We consider a discrete-time one-sector economy populated by a continuum of identical long-lived agents acting under perfect foresight, whose size is normalized to one, and a representative firm producing under constant returns to scale.

Consumers. The representative consumer maximizes a discounted stream of utility functions $\sum_{t=0}^{\infty} \beta^{t} u\left(c_{t}\right)$, where $\beta \in(0,1)$ is the discount factor, $c$ the consumption demand and the per-period utility function $u$ satisfies the following basic restrictions:

Assumption 1 The single-period utility function $u(c)$ is twice continuously differentiable for all positive values of $c$ and satisfies, for any $c>0, u^{\prime}(c)>0$, $u^{\prime \prime}(c)<0, \lim _{c \rightarrow 0} u^{\prime}(c)=+\infty$ and $\lim _{c \rightarrow+\infty} u^{\prime}(c)=0$.

In each period $t$, households face a dynamic budget constraint $B_{t} \equiv r_{t} k_{t}+$ $w_{t}+\left(M_{t}+\tau_{t}\right) / p_{t}-\left(c_{t}+k_{t+1}-\Delta k_{t}+M_{t+1} / p_{t}\right) \geq 0$, where $p$ denotes the price of the good, $k$ the physical equipment, $M$ the money balances, $r$ the real rental price of capital, $w$ the real wage, $\Delta \equiv 1-\delta$ with $\delta \in[0,1]$ the depreciation rate of capital, and $\tau$ the nominal lump-sum transfers issued by the government. For 
simplicity, labor supply is assumed to be inelastic: $l_{t}=1$ for every $t \geq 0 .{ }^{4} \mathrm{We}$ suppose in addition that an amount $q \in(0,1]$ of consumption and investment purchases must be paid by cash in the hands of the representative consumer. In other words, agents are subject to an additional cash-in-advance constraint

$$
C_{t} \equiv M_{t} / p_{t}-q\left(c_{t}+k_{t+1}-\Delta k_{t}\right) \geq 0
$$

The consumer maximizes the Lagrangian $\Lambda_{0} \equiv \sum_{t=0}^{\infty} \beta^{t}\left(u\left(c_{t}\right)+\lambda_{t} B_{t}+\nu_{t} C_{t}\right)$, with respect to $\left\{M_{t+1}, k_{t+1}, c_{t}\right\}_{t=0}^{\infty}$, where $\lambda$ and $\nu$ are non-negative multipliers associated to, respectively, the budget constraint and the cash-in-advance. The FOC's for the representative household write:

$$
\begin{aligned}
\lambda_{t} & =\beta\left(\lambda_{t+1}+\nu_{t+1}\right) p_{t} / p_{t+1} \\
u^{\prime}\left(c_{t}\right) & =\lambda_{t}+q \nu_{t} \\
\lambda_{t}+q \nu_{t} & =\beta\left[\left(\Delta+r_{t+1}\right) \lambda_{t+1}+q \Delta \nu_{t+1}\right]
\end{aligned}
$$

According to the arbitrage condition (2), the price of money at time $t, \lambda_{t}$, is equal to its expected value in the following period plus the expected value of the implicit dividends $\nu_{t+1}$ it will pay off. At the same time, $\lambda_{t}$ can be viewed as the marginal indirect utility of real income in period $t$. However, as (3) establishes, at the optimum it does not equalize the marginal utility of consumption, since the individual cannot transform income into consumption, unless part of the former was previously held in form of money balances. Condition (4) is the intertemporal consumption-saving decision, which embodies the fractional liquidity constraint on physical investment.

In addition, the transversality condition must be satisfied:

$$
\lim _{t \rightarrow+\infty} \beta^{t} u^{\prime}\left(c_{t}\right)\left(k_{t+1}+\pi_{t+1} m_{t+1}\right)=0
$$

where $m_{t} \equiv M_{t} / p_{t}$ are the real balances held by the representative agent at the outset of period $t-1$ and $\pi_{t+1} \equiv p_{t+1} / p_{t}$ is the gross inflation factor between period $t$ and period $t+1$.

Firms. The (aggregate) representative firm produces the good by mean of a standard constant returns to scale technology: $Y=F(K, L)$, where $K$ and $L$ stand, respectively, for aggregate capital and labor.

Assumption 2 The production function $F: R_{+}^{2} \rightarrow R_{+}$is twice continuously differentiable, increasing in each argument, concave, homogeneous of degree one and such that for any $y>0, \lim _{x \rightarrow 0} F_{1}(x, y)=\lim _{x \rightarrow 0} F_{2}(y, x)=+\infty$, $\lim _{x \rightarrow+\infty} F(x, y)=\lim _{x \rightarrow+\infty} F_{2}(y, x)=0$.

\footnotetext{
${ }^{4}$ We have also considered the case of endogenous labor supply in an appendix available from the authors upon request. Analytical results are more complicated expressions involving the structural parameters.
} 
Profit maximization implies that in each period $t$ the real interest rate and the real wage equalize, respectively, the marginal productivity of aggregate capital and the marginal productivity of aggregate labor: $r_{t}=f^{\prime}\left(k_{t}\right)$ and $w_{t}=f\left(k_{t}\right)-k_{t} f^{\prime}\left(k_{t}\right)$, where $k \equiv K / L$ and $f(k) \equiv F(k, 1)$ denote, respectively, the capital intensity and the per-worker average productivity. Assumption 2 implies that $f$ is increasing and concave.

Monetary authority. The monetary authority is assumed to follow a constant money growth rule. This means that, in each period $t$, the money supply is given by $M_{t}^{s}=\mu^{t} M_{0}^{s}$, where $\mu>0$ is the constant money growth factor, and $M_{0}^{s}$ is the amount of nominal balances available in period zero. Money created at each period is injected to the economy through lump-sum transfers $\tau_{t}=(\mu-1) M_{t}^{s}$ to the consumers. We further assume:

Assumption 3 the money growth factor is strictly larger than the discount factor: $\mu>\beta$

As we will show in the sequel, Assumption 3 ensures that constraint (1) binds in a neighborhood of the steady and that all the relevant variables of the model evaluated at the steady state are strictly positive.

\subsection{Intertemporal equilibrium}

Since the population size is normalized to one, it follows that equilibrium in factors market is obtained by setting $K_{t}=k_{t}$ and $L_{t}=l_{t}$ for every $t \geq 0$. When constraint (1) binds, money market equilibrium implies

$$
\frac{p_{t+1}}{p_{t}} \frac{c_{t+1}+k_{t+2}-\Delta k_{t+1}}{c_{t}+k_{t+1}-\Delta k_{t}}=\frac{M_{t+1}}{M_{t}}=\mu
$$

for every $t \geq 0$. Eventually, Walras law ensures good market clearing in each period. By opportunely manipulating the first order conditions (2)-(4) and the equilibrium ones, the intertemporal equilibrium of the economy can be described in terms of the dynamic evolution of the vector $\left(k_{t}, c_{t}, \lambda_{t}\right)$.

Definition 1 An interior intertemporal equilibrium with perfect foresight is a strictly positive sequence $\left\{k_{t}, c_{t}, \lambda_{t}\right\}_{t=0}^{\infty}$ satisfying, for every $t \geq 0$, equations

$$
\begin{aligned}
u^{\prime}\left(c_{t}\right) / \beta-u^{\prime}\left(c_{t+1}\right) \Delta & =\lambda_{t+1} f^{\prime}\left(k_{t+1}\right) \\
q \lambda_{t} f\left(k_{t}\right) \mu / \beta+(1-q) \lambda_{t+1} f\left(k_{t+1}\right) & =u^{\prime}\left(c_{t+1}\right) f\left(k_{t+1}\right) \\
c_{t}+k_{t+1}-\Delta k_{t} & =f\left(k_{t}\right)
\end{aligned}
$$

subject to the initial money supply $M_{0}>0$, the initial endowment of capital $k_{0}>0$ and the transversality condition (5). 


\section{$2.2 \quad$ Steady state analysis}

Our first goal is to prove the existence and uniqueness of the deterministic steady state of the dynamic system defined by equations (6)-(8). Actually, we are able to provide the explicit expressions of the steady state values of $k, c$, and $\lambda$, by simply dropping the time index from (6)-(8) and by opportunely rearranging terms. Proceeding in such a way, we get the following expressions: $k=f^{\prime-1}(r), c=(r / \alpha-\delta) k, \lambda=u^{\prime}(c) / \tilde{q}$, where $r=\rho \tilde{q}, \rho \equiv 1 / \beta-\Delta>0$ and $\tilde{q} \equiv 1+q(\mu / \beta-1)>1$. In the following $\alpha \equiv k f^{\prime}(k) / f(k) \in(0,1)$ and $\sigma=-u^{\prime}(c) /\left[c u^{\prime \prime}(c)\right]>0$ will denote, respectively, the capital share in total income and the elasticity of intertemporal substitution evaluated at the steady state.

It is easily verifiable that these stationary values are strictly positive under the domain of validity of Assumption 3. For constraint (1) to be locally binding, the Lagrange multiplier $\nu$, evaluated at the steady state, must be strictly positive, which means, in the light of the first order condition (3), that $u^{\prime}(c)-\lambda$ must be positive. Straightforward computations show that this is actually true if and only if Assumption 3 does hold. It follows that equations (6)-(8) describe intertemporal equilibrium of the economy in a sufficiently small neighborhood of the stationary solution.

Is is also worthwhile to emphasize that, despite the fact that the supply of labor is fixed, money is not superneutral in this economy. From the steady state values given above, it is easy to show that a higher money growth rate decreases consumption and capital per capita at the steady state. As emphasized by Stockman (1981) and Abel (1985), who demonstrated the same kind of results within a similar economy with full cash-in-advance constraint on consumption and investment, this contractionary effect of higher money growth is due to the tax imposed by inflation on the cost of capital investment. Of course, compared to these previous papers, this contractionary effect is mitigated when $q$ is relatively small.

After having provided the expressions (6)-(8) describing the dynamics of the economy, we can now go through the stability analysis.

\section{$3 \quad$ Stability analysis}

In order to study the occurrence of (local) indeterminacy, we follow the usual procedure consisting in analyzing the stability of the deterministic dynamics around the steady state $(k, c, \lambda)$. We linearize system (6)-(8) to obtain $J_{1} v_{t+1}=J_{0} v_{t}$, where $J_{0}, J_{1}$ are Jacobian matrixes evaluated at the steady state and $v_{t} \equiv\left(d k_{t} / k, d c_{t} / c, d \lambda_{t} / \lambda\right)^{T}$. The study of the characteristic polynomial $P_{0}(\lambda) \equiv\left(\lambda-\lambda_{1}\right)\left(\lambda-\lambda_{2}\right)\left(\lambda-\lambda_{3}\right)$ of the forward looking Jacobian matrix $J \equiv J_{1}^{-1} J_{0}$ enables us to locate the eigenvalues $\lambda_{1}, \lambda_{2}, \lambda_{3}$ with respect to the unit circle. More precisely, we study the sign of the polynomial evaluated at $-1,0,1$, to locate its intersections with the axis of abscissas: this allows, when the eigenvalues are real, to characterize their modulus and sign. For sake 
of simplicity, instead of studying the characteristic polynomial $P_{0}$, we study the linear transformation $P_{1}=\theta_{0} P_{0}$, where $\theta_{0} \equiv(\Delta-\varkappa / \beta) \tilde{q} / \sigma<0$, with $\varkappa \equiv(\beta / \mu)(\tilde{q} / q)$, is a reduced parameter which is always greater than one. Therefore, we obtain $P_{1}(0)=-(r+\Delta) \tilde{q} /(\beta \sigma), P_{1}(1)=r \varkappa(1-\alpha)(r / \alpha-\delta)$ and $P_{1}(-1)=\theta_{2} / \sigma-\theta_{1}$, where $\theta_{1} \equiv r(r / \alpha-\delta)[2-(1-\alpha) \varkappa]$ and $\theta_{2} \equiv$ $2 \tilde{q}(1+\Delta+r)[(\varkappa-1) / \beta-\Delta]$.

The next Proposition is the main result of the paper and characterizes the local stability of the system defined by equations (6)-(8). It is shown that all the eigenvalues are real, that there exists one which is always stable and one that lies always outside the unit circle. By contrast, the stability of the third eigenvalue depends upon the structural parameters of the model. Namely, when the amplitude of the financial constraint applying on consumption and investment expenditures is low enough (smaller than a certain threshold $q_{1}$ ), the third eigenvalue belongs to $(-1,0)$ and thus equilibrium is locally indeterminate for whatever elasticity of intertemporal substitution in consumption. By contrast, when the amplitude of the liquidity constraint is high enough (greater than a second threshold $\left.q_{2}>q_{1}\right)$, the third eigenvalues belongs to $(-\infty,-1)$ and the equilibrium is locally determinate. In the intermediate case $q_{1}<q<q_{2}$, indeterminacy prevails only for strong enough income effects in intertemporal substitution in consumption (or high relative risk aversion), as measured by parameter $\sigma$.

To be specific, let $q_{1}, q_{2}$ and $\sigma^{*}$ be, respectively, the solutions of $\theta_{1}=0$, $\theta_{2}=0$ and $P_{1}(-1)=0$, that is $\sigma^{*}=\theta_{2} / \theta_{1}$. We obtain

$$
\begin{aligned}
q_{1} & \equiv \frac{1}{1+\frac{\mu}{\beta} \frac{1+\alpha}{1-\alpha}} \\
q_{2} & \equiv \frac{1}{1+\mu \Delta} \\
\sigma^{*} & =\left(\frac{1+\Delta+r}{\rho(r / \alpha-\delta)}\right)\left(\frac{(\varkappa-1) / \beta-\Delta}{1-\varkappa(1-\alpha) / 2}\right)
\end{aligned}
$$

It is straightforward to verify that $0<q_{1}<q_{2}<1$. Using these definitions, we can now formulate:

Proposition 1 Consider the dynamic system under perfect foresight defined by (6)-(8) and its corresponding (unique) steady-state. The three eigenvalues associated to this system are real, with $\lambda_{1}<0<\lambda_{2}<1<\lambda_{3}$. Moreover:

(1) If $0<q<q_{1}$, then $\lambda_{1}>-1$ and the steady-state is locally indeterminate.

(2) If $q_{1}<q<q_{2}$ : For $\sigma<\sigma^{*}, \lambda_{1}>-1$ and the steady state is locally indeterminate; For $\sigma>\sigma^{*}, \lambda_{1}<-1$ and the steady state is locally determinate. In addition, when $\sigma$ goes through $\sigma^{*}$, the steady state undergoes a flip bifurcation.

(3) If $q_{2}<q \leq 1$, then $\lambda_{1}<-1$ and the equilibrium is locally determinate.

Proof. See the Appendix.

Proposition 1 generalizes the case studied by Stockman (1981) and Abel (1985) of an economy with full liquidity constraint on aggregate income. The 
main results emphasized by this proposition are illustrated in the lower panel of Figure 1, where the regions delimited by the critical parameters $q_{1}, q_{2}$ and $\sigma^{*}$ are depicted in the $(q, \sigma)$ plane. For comparison purposes, the upper panel of this figure also displays these results for the alternative reference economy where the liquidity constraint applies to consumption only. ${ }^{5}$

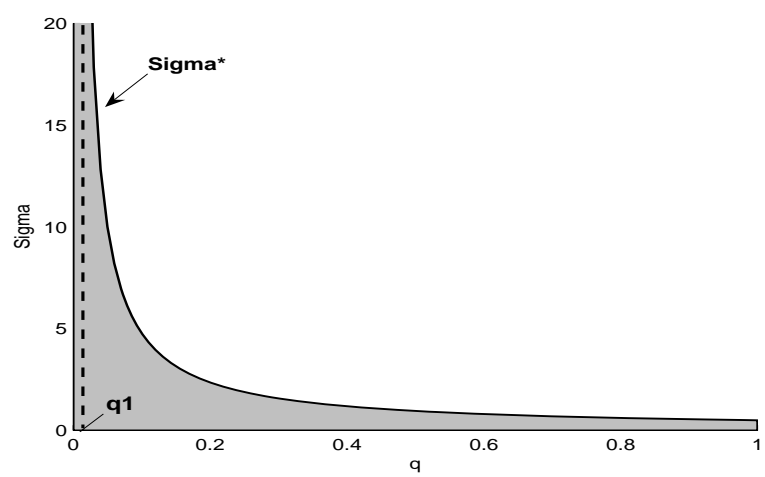

Liquidity constraint on consumption only

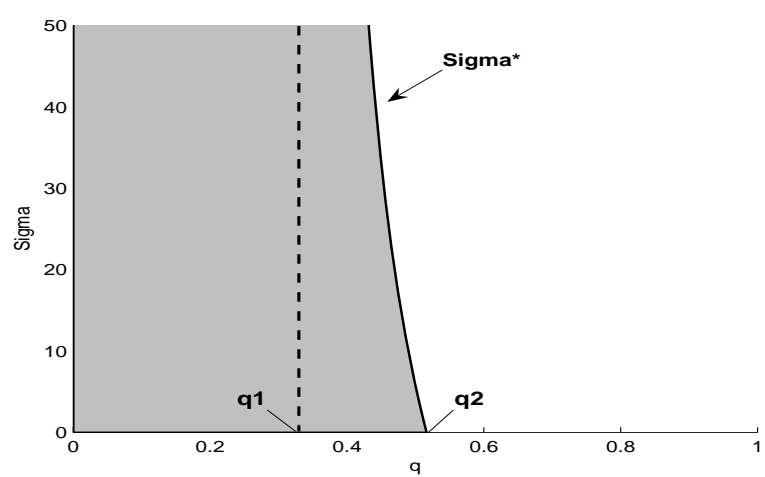

Liquididty constraint on consumption and investment

Figure 1: Indeterminacy regions in the two benchmark economies

One striking feature emerging from Figure 1 is that the inclusion of investment in the liquidity constraint has dramatic effects on the stability properties of the model, as it modifies considerably the range of parameters values giving rise to indeterminacy. However, these effects do not point uniformly toward an increased (or a decreased) instability when the liquidity constraint applies to a fraction of total income. As may be seen, the critical threshold $q_{1}$ below which the steady-state is always indeterminate, which was small and even close to zero in the consumption-based constraint, is strongly increased by the inclusion of

\footnotetext{
${ }^{5}$ We have used in both graphics the same standard annual calibration for the structural parameters: $\beta=0.95, \mu=1.04, \delta=0.1$ and $\alpha=0.3$. See Bosi and Magris (2003) for an explicit analytical derivation of the critical values in the consumption-based liquidity constraint case.
} 
investment in that constraint (reaching a value of $q_{1}=0.34$ ). But, at the same time, this inclusion of investment also creates a second threshold $q_{2}$ above which the steady-state is always determinate (threshold which, using the standard annual calibration mentioned above, is approximately around 0.51 ). Finally, when the share $q$ lies in the $\left[q_{1}, q_{2}\right]$ interval, indeterminacy depends on the relative risk aversion of consumers. The critical value for $\sigma$ below which the steady-state is indeterminate is defined implicitly by a locus $\sigma^{*}=\sigma(q)$ which tends to decrease from $+\infty$ to 0 as $q$ increases from $q_{1}$ to $q_{2}$. Note however that, for the standard calibration considered, this locus has a slope which is very steep in the $(q, \sigma)$ plane. This implies that, in most of this interval, indeterminacy prevails for a large range of values of $\sigma$ including all empirically plausible estimates.

It results from this analysis that the fraction of consumption and investment purchases requiring cash is the crucial parameter to determine whether constant money growth rules are likely to prone stability and rule out sunspot fluctuations in this economy. From an empirical perspective, it is interesting to observe that this parameter can be given another interpretation in terms of money velocity. Indeed, equation (1) implies, when it is binding, that $M_{t} / p_{t}=$ $q\left(c_{t}+k_{t+1}-\Delta k_{t}\right) \equiv q y_{t}$, where $y_{t}$ is aggregate output. Hence, the parameter $q$ appears as the (inverse of) the steady-state velocity of money, a parameter about which the literature provides empirical estimates. Interpreting money to be the money base, Carlstrom and Fuerst (2003) report a value of $q=1 / 3$, which falls in the indeterminacy region depicted in Figure 1. However, Orphanides and Porter (2000) provide a more detailed empirical analysis using data on M2 which leads to slightly different estimates. One central result in their paper, which is particularly interesting from our perspective, is that they find that the steady state velocity of money has tended to increase during the recent decades, rising from a value of 1.70 in the 60 's and 70 's to a value higher than 2 in the 90's. This corresponds, respectively, to estimates for $q$ of 0.59 and 0.5 , suggesting that the economy was in the determinacy region during most of the recent decades. Note however that the second value falls very close to $q_{2}$, the second threshold below which the equilibrium quickly becomes indeterminate. Hence, if the upward trend for money velocity were to be confirmed in the future, the model suggests that adopting a money growth targeting rule might not easily achieve stability - a topic which is already a concern for the currently used interest rate policy rule.

\section{Conclusion}

In this paper, we have studied the stability properties of a one-sector productive economy under constant money growth rules, when agents are subject to a partial cash-in-advance constraint applying on consumption and investment purchases. It appears from our analysis that taking liquidity constraints on investment into account have considerable effects on the range of parameters values giving rise to local indeterminacy. In particular, we found that money growth targeting rules uniformly ensure equilibrium determinacy when the liq- 
uidity constraint is strong, but may favor the emergence of expectation-driven fluctuations if that constraint is weak. In the data, the partial liquidity constraint may be approximated by the inverse of the steady-state velocity of money. While the postwar US data seem to suggest that the economy was until recently in the determinacy region, the recurrent tendency for money velocity to increase in recent decades, traducing the increase in transaction facilities due to the introduction of more liquid assets and new forms of payments, may well reverse soon this conclusion.

\section{Appendix}

Proof of Proposition 1. First, recall that the characteristic polynomial $P_{1}(\lambda)$ is a continuous function and that its domain is connected. We observe that $P_{1}(0)<0$ and $P_{1}(1)>0$. Moreover, $\theta_{0}<0$ implies $\lim _{\lambda \rightarrow+\infty} P_{1}(\lambda)=-\infty$. Then $\lambda_{1}<0<\lambda_{2}<1<\lambda_{3}$. In order to know whether $\lambda_{1}$ is greater than -1 , we solve the inequality $P_{1}(-1)>0$. If $\theta_{1}<0$, then $\theta_{2}>0$ and $\theta_{2} / \sigma-\theta_{1}=$ $P_{1}(-1)>0$. If, on the other hand, $\theta_{1}>0$, then $P_{1}(-1)>0$, if and only if $\sigma<\sigma^{*} \equiv \theta_{2} / \theta_{1}$. In other words, $\lambda_{1}>-1$, if and only if either $\theta_{1}<0$ or $\sigma<\sigma^{*}$. But $\theta_{1}<0$ is equivalent to $q<q_{1}$, while $\sigma^{*}<0$, with $\theta_{1}>0$, to $\theta_{2}<0$, that is $q>q_{2}$. It follows that for $q<q_{1}, \lambda_{1}>-1$ whatever $\sigma$, while $q_{1}<q<q_{2}$ implies $\lambda_{1}>-1$, if and only if $\sigma<\sigma^{*}$. Eventually, if $q>q_{2}, \lambda_{1}<-1$. A flip bifurcation arises when $\sigma=\sigma^{*}$.

\section{References}

[1] Abel A. B. (1985). Dynamic Behavior of Capital Accumulation in a Cashin-Advance Model. Journal of Monetary Economics 16, 55-71.

[2] Benhabib, J., S. Schmitt-Grohé and M. Uribe (2001). The Perils of Taylor Rules. Journal of Economic Theory 96, 40-69.

[3] Bosi, S., and F. Magris (2003). Indeterminacy and Endogenous Fluctuations with Arbitrarily Small Liquidity Constraint. Research in Economics 57, 39-51.

[4] Carlstrom, C. T., and T. S. Fuerst (2003). Money Growth Rules and Price Level Determinacy. Review of Economic Dynamics 6, 263-75.

[5] Cooley, T. F., and G. D. Hansen (1989). The Inflation Tax in a Real Business Cycle Model. American Economic Review 79, 492-511.

[6] Feenstra, R. C. (1986). Functional Equivalence between Liquidity Costs and the Utility of Money. Journal of Monetary Economics 17, 271-91.

[7] Grandmont, J.-M., and Y. Younès (1972). On the Role of Money and the Existence of a Monetary Equilibrium. Review of Economic Studies 39, 35572 . 
[8] Lucas, R. E., and N. Stokey (1987). Money and Interest in a Cash-inAdvance Economy. Econometrica 55, 491-513.

[9] Matsuyama, K. (1990). Sunspot Equilibria (Rational Bubbles) in a Model of Money-in-the-Utility-Function. Journal of Monetary Economics 25, 137144.

[10] Orphanides, A., and Porter, R. D. (2000). $P^{*}$ Revisited: Money Based Inflation Forecasts with a Changing Equilibrium Velocity. Journal of Economics and Business 52, 87-100.

[11] Stockman, A. C., (1981). Anticipated Inflation and the Capital Stock in a Cash-in-Advance Economy. Journal of Monetary Economics 8, 387-93.

[12] Woodford, M., (1994). Monetary Policy and Price Level Determinacy in a Cash-in-Advance Economy. Economic Theory 4, 345-80. 